Ortega Montequín, M. (2019): "La accesibilidad peatonal a dotaciones de proximidad como pauta para la ordenación urbana. Oviedo como ejemplo metodológico", GeoFocus (Artículos), $n^{\circ}$ 23, p. 3-18. ISSN: 1578-5157 http://dx.doi.org/10.21138/GF.629

\title{
LA ACCESIBILIDAD PEATONAL A DOTACIONES DE PROXIMIDAD COMO PAUTA PARA LA ORDENACIÓN URBANA. OVIEDO COMO EJEMPLO METODOLÓGICO.
}

\author{
MARCOS ORTEGA MONTEQUÍN ${ }^{1}$ \\ Profesional independiente \\ ${ }^{1}$ igeocart@gmail.com
}

\section{RESUMEN}

Para mejorar la calidad de vida urbana son relevantes las dotaciones de proximidad, tales como los equipamientos sanitarios de atención primaria, los centros escolares o las zonas verdes. El planeamiento urbanístico general, por su lado, ha atendido más al cumplimiento de estándares numéricos que a la localización de las mismas. En este artículo se relata el análisis empleado en los estudios previos para la revisión del planeamiento general de Oviedo a partir de la accesibilidad peatonal a las dotaciones de proximidad.

Palabras clave: Dotaciones, equipamiento, zona verde, accesibilidad peatonal, planeamiento urbanístico.

PEDESTRIAN ACCESSIBILITY TO PROXIMITY PUBLIC FACILITIES AS A MODEL FOR URBAN PLANNING. OVIEDO AS A METHODOLOGICAL EXAMPLE.

\section{ABSTRACT}

To improve the quality of urban life, the proximity public facilities are relevant, such as primary health clinic, schools or green areas. The municipal urban planning has served more to comply with numerical standards than the location of them. This article related the analysis used in the previous studies for the review of the urban planning of Oviedo from the pedestrian accessibility to proximity facilities.

Keywords: Facilities, equipment, green area, pedestrian accessibility, urban planning.

\section{Introducción y objetivos}

Junto con la clasificación y calificación del suelo, los sistemas constituyen la base de la ordenación en los planeamientos generales municipales. Los sistemas, generales o locales, son dotaciones urbanísticas, "suelo destinado a un determinado uso, especialmente al de instalaciones 
Ortega Montequín, M. (2019): "La accesibilidad peatonal a dotaciones de proximidad como pauta para la ordenación urbana. Oviedo como ejemplo metodológico", GeoFocus (Artículos), $n^{\circ}$ 23, p. 3-18. ISSN: $1578-5157$ http://dx.doi.org/10.21138/GF.629

públicas" (DRAE, 2017) y que según la reglamentación vigente se corresponden con viario público, equipamientos, servicios urbanos, zonas verdes y espacios libres ${ }^{1}$.

Dentro de las dotaciones, los equipamientos y las zonas verdes deben cumplir con determinados estándares, habitualmente relacionando superficie de la dotación por habitante, lo que garantiza que estas dotaciones presenten superficies adecuadas (en Asturias, $5 \mathrm{~m}^{2} / \mathrm{hab}$., tanto en equipamientos como en zonas verdes, en su condición de sistema general que da servicio al conjunto de la población). Sin embargo, contar con un estándar suficiente no siempre evita que estas dotaciones puedan presentar disfuncionalidades a la hora de dar servicio a sus demandantes potenciales, especialmente cuando la proximidad a la residencia es determinante; con ello, sin que haya un déficit de equipamientos en términos de ratio superficie/habitantes, puede darse el caso de que no sirvan adecuadamente a determinadas áreas.

Bajo esta premisa, el presente artículo tiene como objetivo el análisis de accesibilidad peatonal de los equipamientos de proximidad y zonas verdes y espacios libres del municipio de Oviedo (Asturias) en relación con las viviendas existentes, detectando las áreas donde el servicio es deficiente por existir una distancia excesiva que limite su accesibilidad peatonal y que conlleve que desde dichas áreas se tienda a efectuar desplazamientos utilizando medios transporte (espacios "en sombra").

La investigación queda incardinada dentro de los estudios previos efectuados para la revisión del Plan General de Ordenación de Oviedo, con objeto de, en las fases de ordenación, tomar determinaciones que permitan paliar un deficiente acceso a estas dotaciones.

Este artículo se inicia con una compilación de experiencias en trabajos similares, seguido de una descripción de los métodos empleados en el caso concreto que se toma como ejemplo, la presentación de los resultados obtenidos y el contraste con otros métodos con los que se efectuaron pruebas.

\section{Estado de la cuestión}

Dado el eminente carácter aplicado del tema que se aborda, cabe diferenciar entre los antecedentes de carácter científico/académico y los procedentes del propio proceso de redacción de planeamientos municipales.

Entre los primeros, en la mayor parte de los casos hacen referencia a un equipamiento concreto (centros sanitarios y centros escolares casi en su totalidad, como se evidencia en las referencias bibliográficas), decantándose, fundamentalmente, por técnicas euclidianas y análisis vectoriales de red.

De todos modos, hay que iniciar este apartado mencionando el trabajo de Basoa Rivas y Oterio Puime (1994), por ser el precursor en materia de análisis de la accesibilidad física a centros de salud enfocada hacia el planeamiento urbanístico, a pesar de emplear todavía técnicas "analógicas".

Las técnicas euclidianas son las más sencillas, pues miden la distancia lineal desde un equipamiento, generando formas de anillos concéntricos. Así, Arranz et al (2012) indican que "se ha realizado el cómputo mediante áreas generadas por distancias euclidianas, después de rechazar otros métodos basados en el desarrollo de una red topológica que crease un desplazamiento mediante itinerarios, por las dificultades que presentaba"; procedimientos similares son también los 
Ortega Montequín, M. (2019): "La accesibilidad peatonal a dotaciones de proximidad como pauta para la ordenación urbana. Oviedo como ejemplo metodológico", GeoFocus (Artículos), $n^{\circ} \quad 23, \quad$ p. 3-18. ISSN: $1578-5157$ http://dx.doi.org/10.21138/GF.629

publicados por Escalona Orcao y Díez Cornago (2003 y 2005), quienes añaden índices correctores al análisis, o por De la Fuente et al (2013), quienes completan el análisis de distancia con otras variables. Las unidades de medida de estos métodos suelen ser de longitud.

Las técnicas vectoriales basadas en análisis de redes son de uso muy frecuente. Entre ellas cabe destacar las diferentes publicaciones de Ramírez (2003, 2006 y 2009), muy completas y con un enfoque hacia el sistema sanitario de escala regional y metropolitana; Prat et al. (2008 y 2009) en una línea similar sobre el sistema sanitario regional; o la de Esquivel-Cuevas et al. (2013) que incluye, entre otros correctores, el ancho de acera, obstáculos o dispositivos de control del tráfico; García-Palomares et al. (2018), por su parte, emplean los análisis de redes vectoriales para ensayar modelos para la futura urbanización en relación con la red de metro; Moro y Villaescusa (2000) pueden citarse también como ejemplo. Lo usual es que estas técnicas usen el tiempo como unidad de medida.

Los procedimientos de análisis ráster, si bien se citan en algunas de las publicaciones mencionadas, por ejemplo Ramírez (2006), son poco frecuentes, aunque hay ejemplos como el de Ortega Montequín y Méndez García (2012).

En cuanto a las escalas de aplicación, si bien son muy diferentes, tienden a destacar las regionales o metropolitanas frente a otras de mayor detalle, como la municipal o inframunicipal; del mismo modo, el transporte particular en vehículo de motor es el más recurrente.

Por su lado, los planeamientos generales municipales tienden más a preocuparse de cumplir los estándares que de la correcta distribución de las dotaciones, que acaban subordinadas a los propios desarrollos, a lo que cabe añadir que la mayor parte de los municipios cuentan con tan poca población que la existencia o planificación de equipamientos suele exceder sus términos municipales. Excepciones son, al menos en su fase de análisis, los casos de Bilbao (Avance, 2016) y Vigo (Borrador -equivalente al Avance-, 2016), empleándose en ambos técnicas euclidianas para el caso de los equipamientos; no se tiene constancia de que se hayan aplicado análisis de accesibilidad a zonas verdes.

\section{3. Área y objeto del estudio}

\subsection{Delimitación del área de estudio}

El planeamiento a revisar tiene como ámbito espacial el término municipal de Oviedo, capital de la Comunidad Autónoma del Principado de Asturias (España), situado en una posición central dentro de la región y de un área metropolitana policéntrica que aglutina en torno al $80 \%$ de la población asturiana, cuyos núcleos principales son Gijón, Oviedo (ambas ciudades totalizan casi la mitad de los habitantes de Asturias), Avilés, Langreo y Mieres. Oviedo presenta las siguientes cifras.

- Superficie municipal: $186 \mathrm{~km}^{2}$.

- Población: 220.488 habitantes en 2018, según datos facilitados por la oficina de estadística municipal.

- Viviendas: 125.495 en 2017, según estudio de la revisión del planeamiento. 


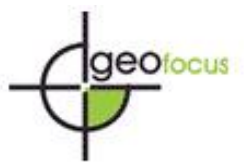

Revista Internacional de Ciencia y Tecnología de la Información Geográfica International Review of Geographical Information Science and Technology

Ortega Montequín, M. (2019): "La accesibilidad peatonal a dotaciones de proximidad como pauta para la ordenación urbana. Oviedo como ejemplo metodológico", GeoFocus (Artículos), $n^{\circ} \quad 23, \quad$ p. 3-18. ISSN: 1578-5157 http://dx.doi.org/10.21138/GF.629

Sin embargo, para el estudio que aquí se describe no se consideró oportuno emplear el municipio entero, pues el poblamiento se distribuye en 39 aldeas, 141 caserías, 75 lugares, una ciudad y un barrio según el nomenclátor del INE; y en áreas de poblamiento disperso la aplicación de la accesibilidad peatonal no resulta un buen indicador por varios motivos: entidades de reducidas dimensiones y escasas dotaciones, muy baja densidad de población y de construcción, lo que redunda en distancias largas, viario poco adaptado a una circulación no motorizada... Incluso los núcleos de población urbanos menores (casos de Trubia, Olloniego, Amieves o Tudela Veguín), si bien pueden considerarse como centros inframunicipales, carecen de suficiente entidad para este tipo de análisis.

Por ello, se decidió emplear como área de estudio la ciudad, pero no la que define el nomenclátor, sino siguiendo un criterio morfológico y funcional donde prima la ocupación por áreas residenciales de edificios en altura, áreas de grandes equipamientos (frecuentes por la condición de capital de Oviedo), zonas verdes asociadas y algún área productiva intercalada. Una denominación muy representativa para el área de estudio sería la de "continuo urbano", como refleja la figura 1 , donde se representa sobre el mapa topográfico del IGN.

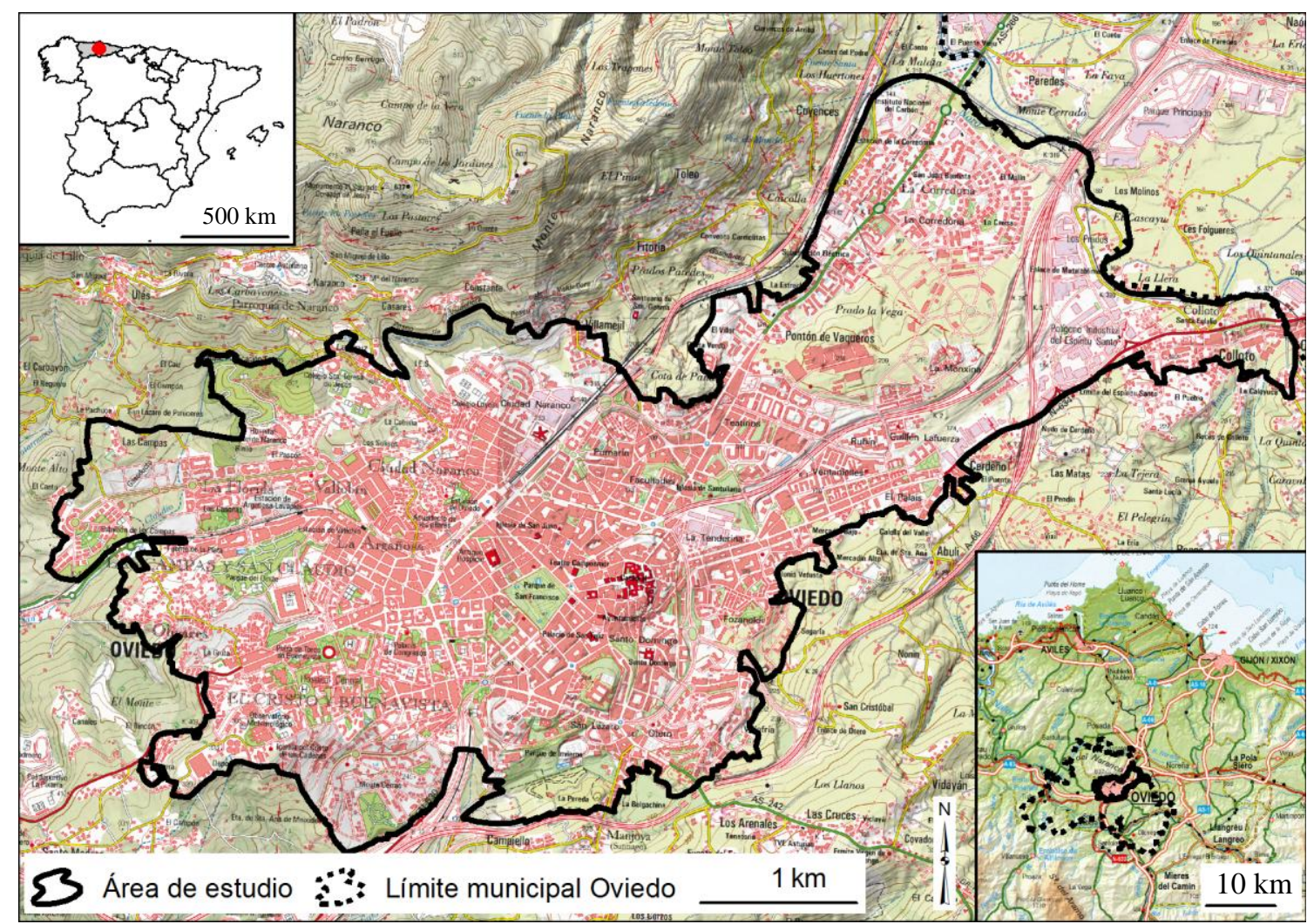

Figura 1. Localización y delimitación del área de estudio.

Base: Servicio WMS de la Cartografía Ráster del IGN

Para la delimitación final del área de estudio se comprobó su adecuada correspondencia con la cartografía catastral, razón por la que se emplearon los límites del catastro de urbana. El área 
Ortega Montequín, M. (2019): "La accesibilidad peatonal a dotaciones de proximidad como pauta para la ordenación urbana. Oviedo como ejemplo metodológico", GeoFocus (Artículos), $n^{\circ} \quad 23, \quad$ p. 3-18. ISSN: $1578-5157$ http://dx.doi.org/10.21138/GF.629

resultante abarca $17 \mathrm{~km}^{2}$ (9\% del municipio), aloja 204.995 habitantes (93\% de la población municipal) y contiene 116.591 viviendas ( $93 \%$ del parque residencial municipal).

\subsection{Las dotaciones de proximidad consideradas}

El Reglamento en materia de urbanismo y ordenación del territorio del Principado de Asturias (ROTU) señala que las dotaciones urbanísticas son vías públicas de comunicación, equipamientos, servicios urbanos, zonas verdes y espacios libres. Ahora bien, dentro de esta definición caben múltiples enfoques, usos y alcances diferentes. Por ello, a efectos prácticos de este estudio, cabe eliminar aspectos como el viario (aparte de que sea la base de la movilidad) y los servicios urbanos (abastecimiento y saneamiento, red eléctrica, etc.), pues se dan por supuestos.

El caso de los equipamientos, sin embargo, puede considerarse como el de mayor complejidad pues su definición ${ }^{2}$ encierra usos y alcances muy diversos. Por ello, el término de "proximidad" cobra relevancia. La figura 2 resulta muy ilustrativa de este concepto, en función del deseo y rechazo de servicios próximos al hogar ${ }^{3}$. En síntesis:

- Los de proximidad son aquellos servicios que suelen contar con un uso ordinario, como el comercio cotidiano (supermercado, panadería, farmacia, etc.), obligado a determinadas edades (centros escolares), o los que son especialmente valorados aunque su uso no sea frecuente, como los centros sanitarios de atención primaria.

- Hay otros servicios que, si bien se estima su proximidad, aceptan un radio mayor por ser menos frecuente su uso, caso de los centros comerciales, de ocio, administración, áreas deportivas, etc.

- Equipamientos como los hospitales son "deseados pero no contiguos" (Olivera, 1993), pues si bien el uso de su servicio de urgencias, consultas y hospitalización suele ser puntual pero vital, las molestias de un intenso trasiego de personas, así como los ruidos asociados al trasporte de emergencias, lo convierten, hasta cierto punto, en una instalación molesta.

- Los más alejados son aquellos servicios hacia los que la población muestra un claro rechazo por su consideración de nocivos, molestos o peligrosos.

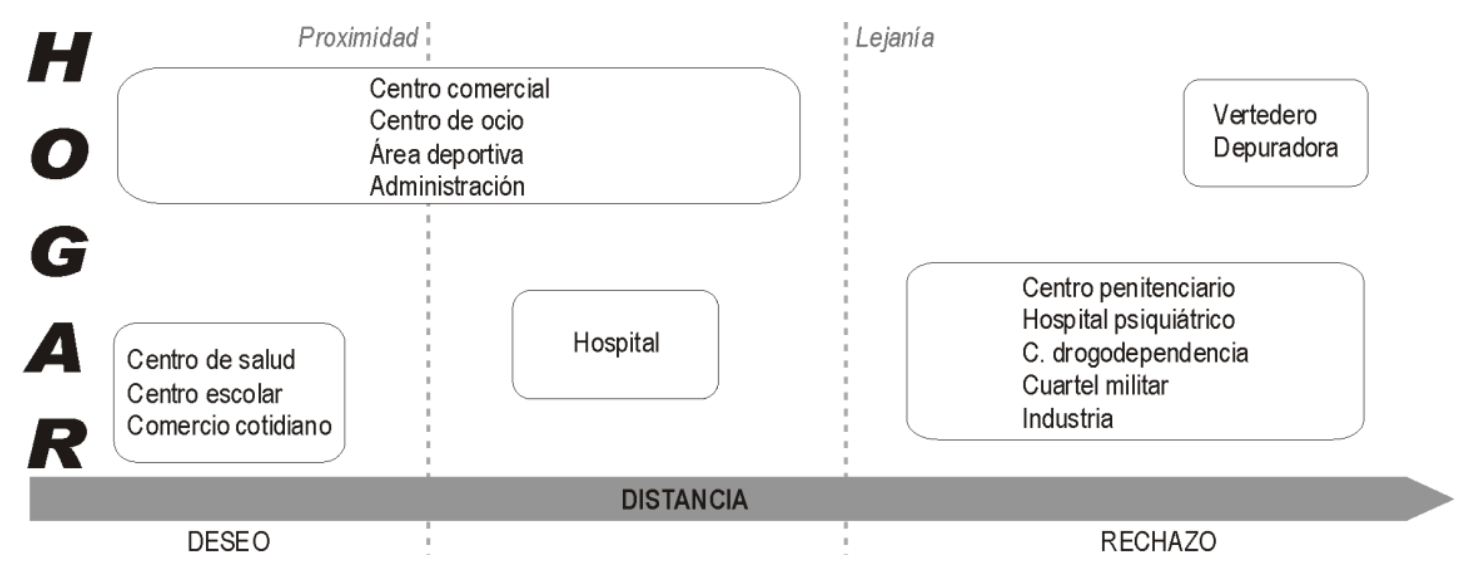

Figura 2. Deseo y rechazo de servicios cerca de la vivienda. Elaboración propia a partir de Olivera (1993). 
Ortega Montequín, M. (2019): "La accesibilidad peatonal a dotaciones de proximidad como pauta para la ordenación urbana. Oviedo como ejemplo metodológico", GeoFocus (Artículos), $n^{\circ}$ 23, p. 3-18. ISSN: $1578-5157$ http://dx.doi.org/10.21138/GF.629

A partir de lo expuesto, los equipamientos de proximidad que cabía incluir en este estudio serían los siguientes:

- Centros sanitarios de atención primaria, en su mayoría centros de salud, si bien para el caso del área de estudio se añadieron dos consultorios periféricos (consultas de un centro de salud en una instalación ajena al propio centro; se emplean para acercar el servicio en áreas de población insuficiente para contar con un centro de salud propiamente dicho). Los datos fueron facilitados por la Consejería de Sanidad del Principado de Asturias y contrastados con la información publicada en la página web oficial de Astursalud.

- Centros de educación obligatoria, tanto primaria como secundaria; en ambos casos se empleó la red "gratuita", compuesta por centros públicos y concertados, analizados separadamente. La información fue facilitada por la Consejería de Educación y Cultura del Principado de Asturias, así como completada con el mapa escolar de la web oficial de Educastur.

- Las escuelas infantiles (guarderías) públicas, si bien su proximidad es relevante, sólo hay seis dentro del área de estudio y son periféricas, por lo que se consideró innecesario llegar a análisis detallados dado que el déficit es más que evidente. El servicio lo están cubriendo centros privados.

- Por otra parte, la diferenciación entre zonas verdes y espacios libres que hace el Reglamento se juzga, cuanto menos, artificiosa ${ }^{4}$ y enfocada hacia el cumplimiento de estándares (sólo aplicados a zonas verdes), puesto que su uso tiende a ser el mismo; así, a efectos de este estudio, no se consideró conveniente diferenciarlos, si bien se clasificaron según su tamaño. Éstos se documentaron a través de las diferentes bases topográficas, del planeamiento urbanístico general vigente y de las ortofotografías del PNOA.

\section{Metodología}

\subsection{La herramienta "coste por distancia"}

En este estudio se ha empleado ArcGis versión 10.1, que en su extensión Spatial Analist cuenta con la herramienta Cost Distance, que está incluida en la mayor parte de los Sistemas de Información Geográfica que emplean datos ráster.

"Coste por distancia" es una tipo de herramienta ráster que, básicamente, calcula la distancia de menor coste acumulado para cada celda de la matriz al punto de origen más cercano sobre una superficie en la que están definidos los costes.

Dado que el agente es el peatón, la preparación de los datos consiste, básicamente, en obtener un ráster con el espacio peatonal. Para la obtención de este espacio de tránsito peatonal, fue empleado el shapefile del área de estudio y el de las manzanas del catastro de urbana, se unieron las capas para, posteriormente, restar al área de estudio el espacio ocupado por las manzanas. Después se ajustó eliminando aquellas zonas donde el viario no permite la circulación peatonal, precisando itinerarios en zonas verdes e incluyendo puentes, pasarelas y pasajes. Con ello se obtuvo un shapefile del espacio peatonal. 
Ortega Montequín, M. (2019): "La accesibilidad peatonal a dotaciones de proximidad como pauta para la ordenación urbana. Oviedo como ejemplo metodológico", GeoFocus (Artículos), $n^{\circ} \quad 23, \quad$ p. 3-18. ISSN: $1578-5157$ http://dx.doi.org/10.21138/GF.629

Por otro lado, para facilitar el posterior recuento de viviendas (descrito en el punto 4.2) se efectuó un buffer de 50 centímetros sobre las manzanas para que hubiese superposición entre el espacio viario y las manzanas catastrales.

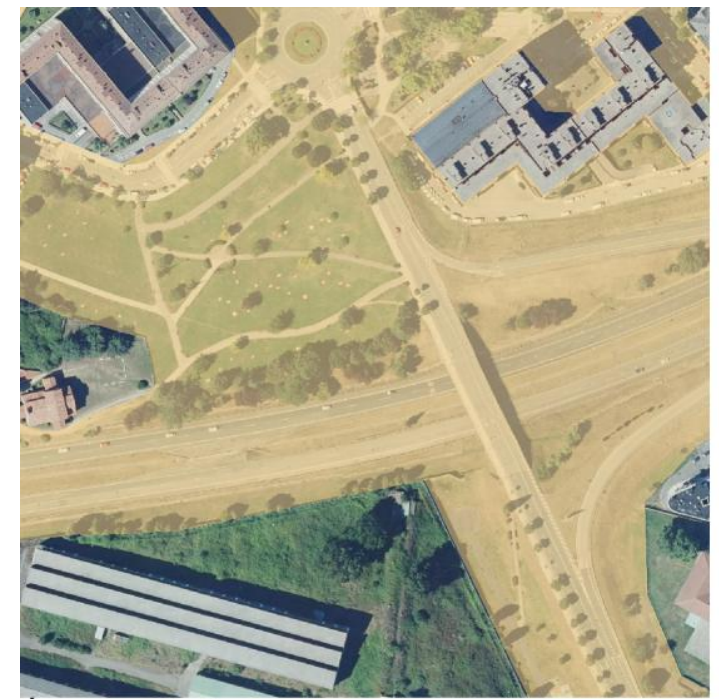

Área de estudio menos manzanas

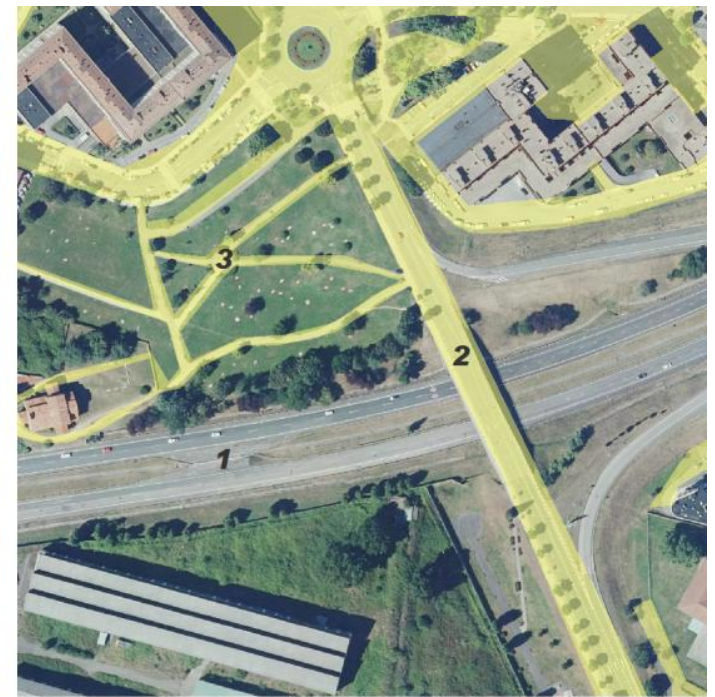

Espacio peatonal tras el tratamiento de los datos

1 Áreas sin circulación peatonal posible 2 Ajuste de puentes y pasarelas 3 Ajuste de zonas verdes

Figura 3. Tratamiento de los espacios de uso peatonal.

$100 \mathrm{~m}$ Base: PNOA 2017.

$\mathrm{Al}$ resultado se le añadieron los atributos necesarios para analizar el coste por distancia. $\mathrm{El}$ coste se mide en minutos, considerando una velocidad constante de 4 kilómetros por hora (15 $\mathrm{min} / \mathrm{km}$ ), velocidad establecida por el método MIDE (Método para la Información de Excursiones) para caminos de herradura (París Roche, 2003); esta velocidad es algo menor de la que desarrolla un adulto sin impedimentos físicos sobre superficies pavimentadas, pero sirve para efectuar cierta corrección en los tiempos de espera de cruces de calzada, así como para acercarlo más hacia personas de menor ritmo en el desplazamiento (niños, ancianos, personas con movilidad reducida, etc.). Finalmente, se convirtió el fichero poligonal resultante a uno ráster de resolución espacial de un metro, utilizando como valor la constante de quince minutos por kilómetro $(0,015$ minutos en pasar de una celda del ráster a otra); el resultado puede observarse en la figura 4.

Finalmente, se emplearon las localizaciones de las dotaciones señaladas en el punto anterior y el coste del ráster mencionado, obteniendo como resultado otro ráster con el espacio peatonal y el tiempo de acceso en minutos (coste mínimo acumulado) a las dotaciones más cercanas. Con objeto de facilitar el posterior análisis de los datos, se optó por reclasificarlo en intervalos de 5 minutos, con un máximo de 30. 
Ortega Montequín, M. (2019): "La accesibilidad peatonal a dotaciones de proximidad como pauta para la ordenación urbana. Oviedo como ejemplo metodológico", GeoFocus (Artículos), $n^{\circ}$ 23, p. 3-18. ISSN: $1578-5157$ http://dx.doi.org/10.21138/GF.629

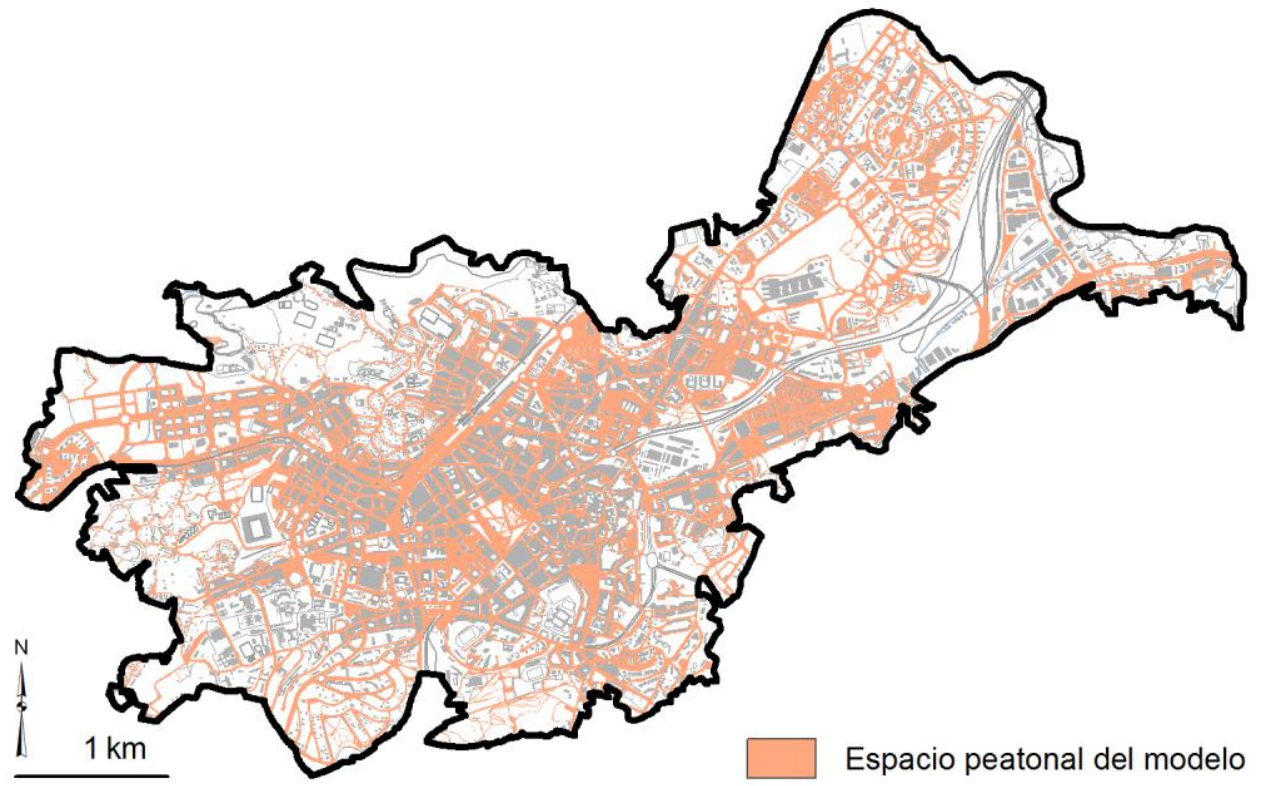

Figura 4. Espacios de uso peatonal considerados en el modelo.

Base: MTN25 vectorial, IGN.

\subsection{La vivienda como unidad de medida}

Es necesario, además, considerar el impacto de las áreas alejadas en relación con la población servida, pues es el elemento que, junto al coste, caracteriza la accesibilidad. Así, no es lo mismo que el área alejada sea un espacio residencial unifamiliar que otro de alta densidad; o incluso que se pueda tratar de áreas industriales y, por tanto, sin residentes.

Lo habitual es que este tipo de análisis utilice como unidad los residentes agrupados por límites estadísticos (barrio, sección censal, etc.); sin embargo, se ha considerado que las viviendas suponen una unidad de medida más estable, como indica su propia condición de "inmueble"; así, a lo largo del tiempo, una misma vivienda puede presentar grados de ocupación diferentes, pero ésta siempre se encontrará a la misma distancia de la dotación a analizar.

Para ello se contó con un estudio específico de la revisión del planeamiento que señala el número de viviendas existentes en cada parcela catastral. Para poder poner en relación las viviendas con los tiempos de acceso peatonal ya se había realizado un buffer de cincuenta centímetros sobre el espacio peatonal, longitud que supone un área lo suficientemente pequeña para no alterar los resultados; ello permitió realizar una intersección entre el espacio peatonal y las parcelas, lo que permitía contar con una estrecha banda con los atributos de viviendas por parcela sobre el espacio peatonal. Para facilitar el cálculo, se convirtieron estas bandas en puntos, forzando que estuviesen dentro de la superficie delimitada, dando como resultado un punto con los atributos de vivienda en un espacio central de la línea de fachada sobre la capa de espacio de tránsito peatonal.

Gracias a ello y mediante consultas espaciales, es posible extraer estadística acerca del número de viviendas por cada tramo de tiempo de acceso peatonal. 
Ortega Montequín, M. (2019): "La accesibilidad peatonal a dotaciones de proximidad como pauta para la ordenación urbana. Oviedo como ejemplo metodológico", GeoFocus (Artículos), $n^{\circ}$ 23, p. 3-18. ISSN: $1578-5157$ http://dx.doi.org/10.21138/GF.629

\section{Resultados}

Se presentan los resultados para Oviedo. Se estructuran en función de cada dotación o grupo de dotaciones concreto, incluyendo en el último punto dos tablas resumen que sintetizan el análisis. Cabe señalar que si bien en el estudio original se hizo un mapa (en formato A3 y escala 1:25.000) para cada una de las dotaciones incluidas en dichas tablas, por el propio medio y formato del artículo se incluyeron sólo aquellos que se consideraron más representativos y ajustados al ancho de página.

\subsection{Los centros sanitarios de atención primaria}

En el área de estudio se encuentran 11 centros de salud a los que cabe añadir dos consultorios periféricos (Las Campas y Colloto, en los respectivos extremos occidental y oriental de la figura 5). Su número y adecuada distribución suponen que por encima de 30 minutos sólo se encuentre un polígono industrial y algunas áreas del oeste pendientes de urbanizar. De hecho, sólo unas 350 viviendas $(0,3 \%$ del total considerado) se encuentran por encima de los veinte minutos de acceso peatonal y menos del $5 \%$ están a más de quince minutos. Por ello, la recomendación de cara al planeamiento, básicamente, se ciñe a contemplar reservas en las áreas de previsible expansión urbana (según planeamiento vigente), fundamentalmente hacia el oeste y sureste, áreas que, a su vez, ya están fuera del rango de quince minutos de acceso.

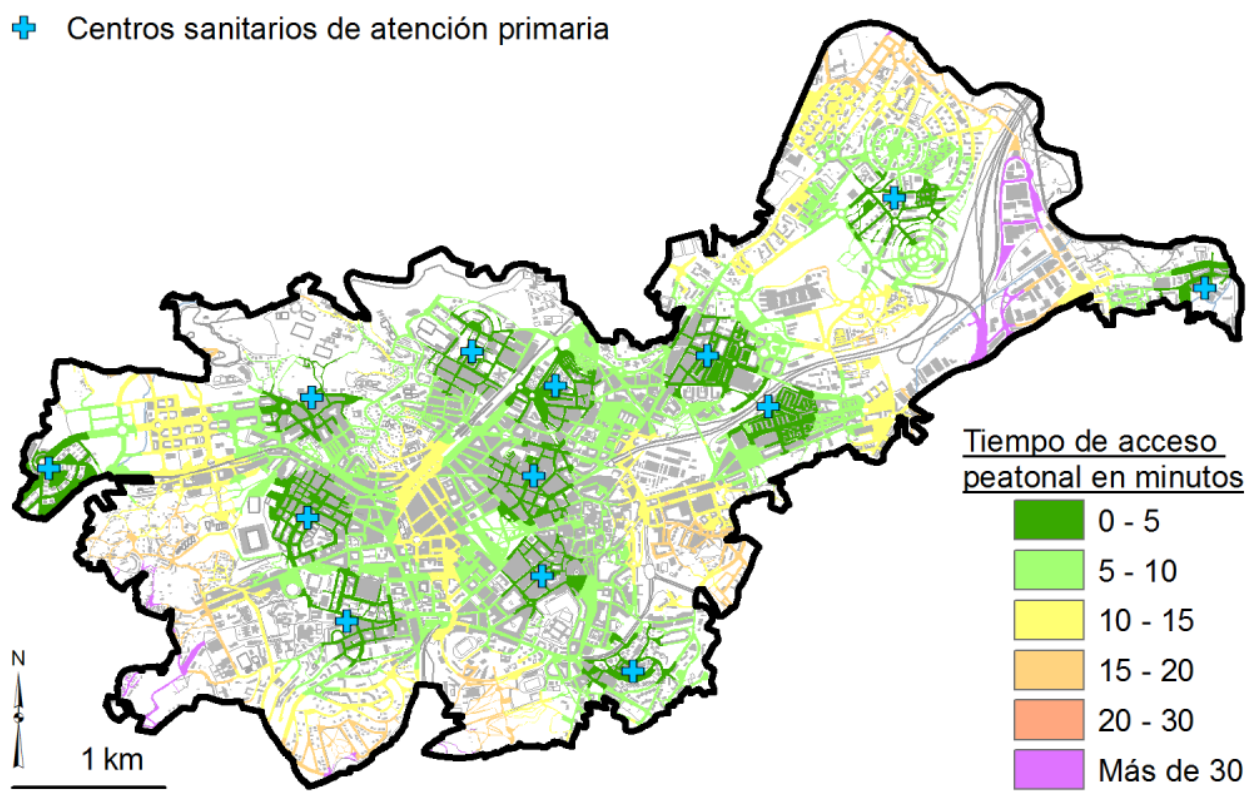

Figura 5. Accesibilidad a centros sanitarios de atención primaria. Fuente: Astursalud. Base: MTN25 vectorial, IGN. 
Ortega Montequín, M. (2019): "La accesibilidad peatonal a dotaciones de proximidad como pauta para la ordenación urbana. Oviedo como ejemplo metodológico", GeoFocus (Artículos), $n^{\circ}$ 23, p. 3-18. ISSN: $1578-5157$ http://dx.doi.org/10.21138/GF.629

\subsection{Los centros escolares}

Los colegios públicos de primaria se encuentran a menos de diez minutos del $85 \%$ de las viviendas; elevando el tiempo a quince minutos, la cifra ya alcanza al $97 \%$. La inclusión de centros concertados en el análisis hace mejorar los estándares, especialmente en los cinco primeros minutos, pero siendo limitada la mejora si se toman en cuenta quince minutos de tiempo de acceso peatonal. Salvo algunos espacios periféricos de baja densidad, el único espacio que se puede considerar "en sombra" es una parte del noroeste (parte central del barrio de La Florida), si bien ya cuenta con un solar calificado para uso educativo.

En lo que respecta a la accesibilidad a centros de secundaria, los tiempos de acceso peatonal son mayores, con casi seis mil viviendas a más de veinte minutos de un centro, aunque las viviendas situadas a menos de quince minutos suponen el $85 \%$ del total; en este caso, los centros concertados tienen una mayor repercusión, especialmente si se reducen a los diez primeros minutos de acceso y muy sensible en zonas como el extremo oriental del área de estudio (Colloto). En este caso, un centro de educación secundaria en el noroeste del área de estudio mejoraría sensiblemente los indicadores.

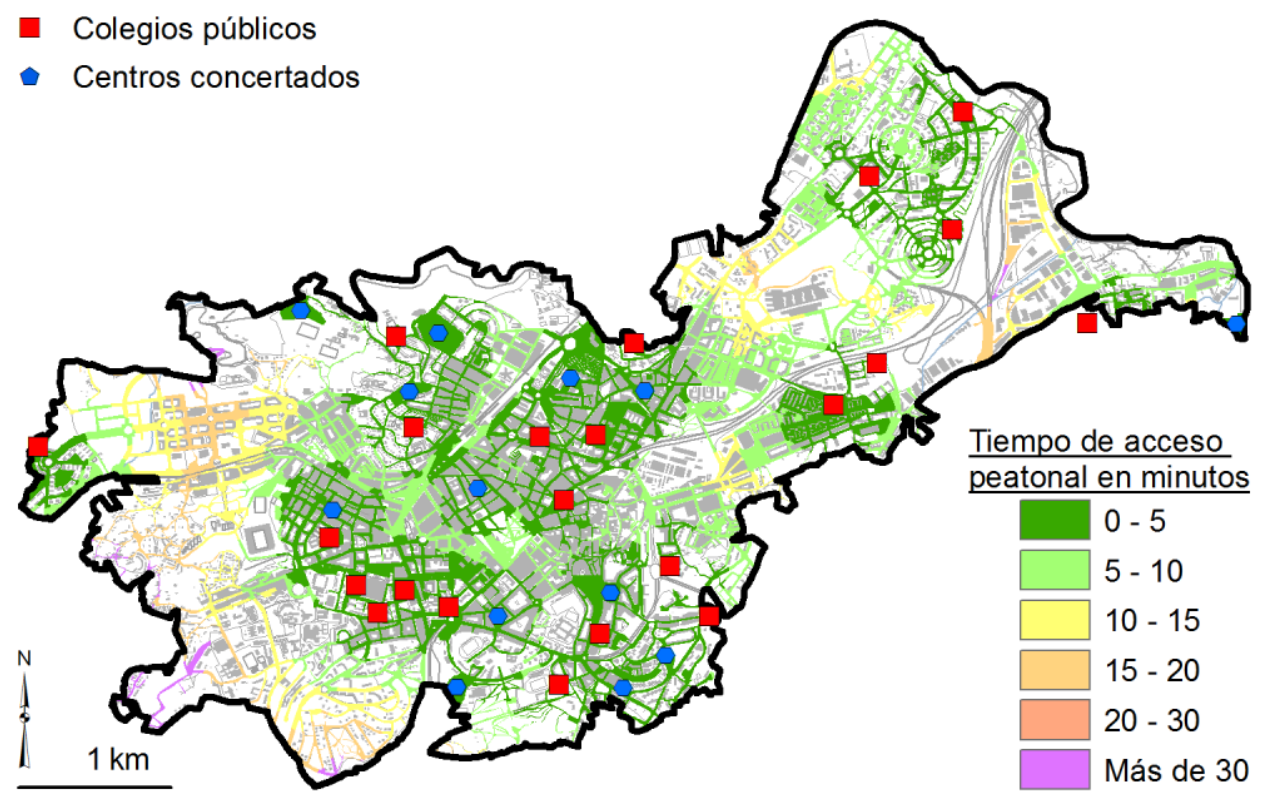

Figura 6. Accesibilidad a centros escolares de educación primaria. Fuente: Educastur. Base: MTN25 vectorial, IGN. 
Ortega Montequín, M. (2019): "La accesibilidad peatonal a dotaciones de proximidad como pauta para la ordenación urbana. Oviedo como ejemplo metodológico", GeoFocus (Artículos), $n^{\circ}$ 23, p. 3-18. ISSN: $1578-5157$ http://dx.doi.org/10.21138/GF.629

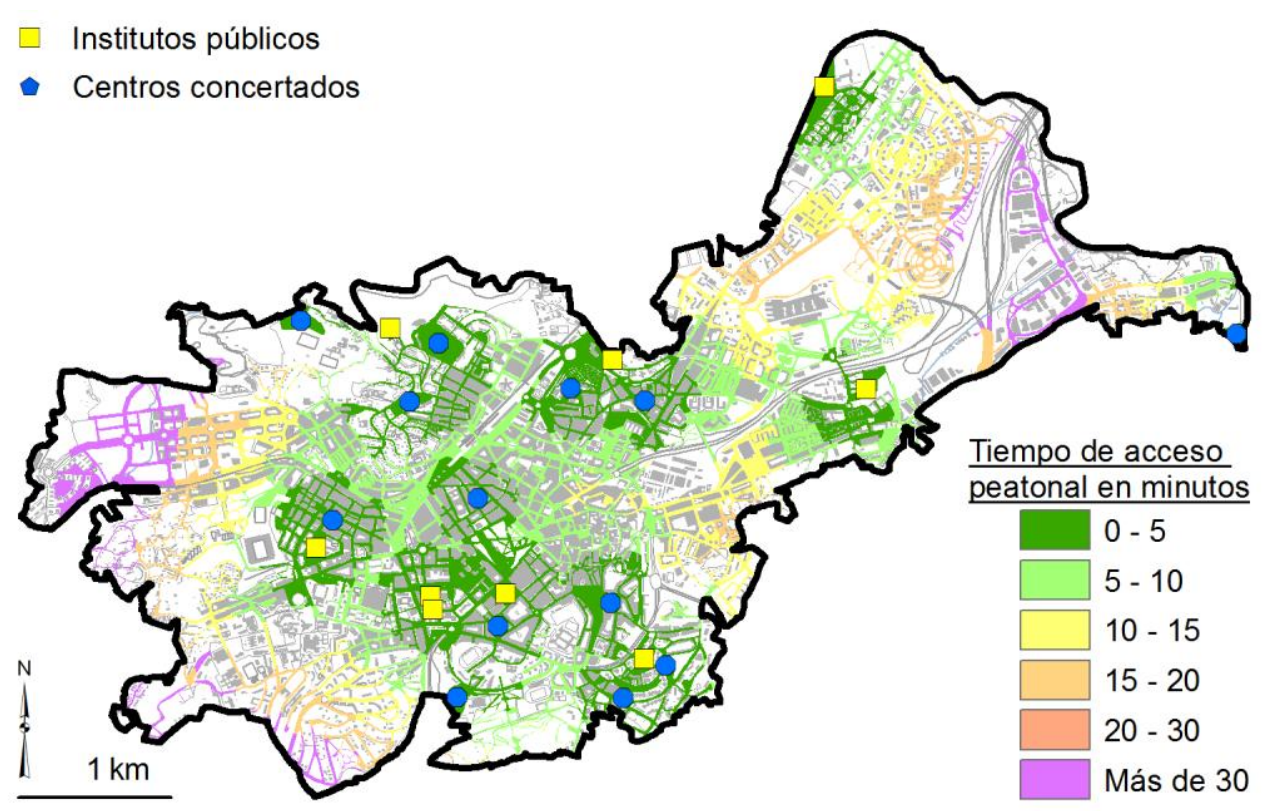

Figura 7. Accesibilidad a centros escolares de educación secundaria. Fuente: Educastur. Base: MTN25 vectorial, IGN.

\subsection{Las zonas verdes y espacios libres}

Como se señala en capítulos anteriores, la diferenciación entre zonas verdes y espacios libres en la reglamentación no resulta especialmente útil; por ello, la opción que mejor se ajusta es su clasificación por superficies, puesto que una vez obtenidos y mínimamente acondicionados los terrenos, las diferencias entre las instalaciones, mobiliarios y ornatos pueden considerarse como algo menor, de sencilla solución y ajeno a la práctica urbanística. Así, se diferenció entre:

- Grandes parques. Son los de mayor superficie, periféricos y conformando un cinturón verde incipiente; a lo que hay que añadir la excepción, el Campo San Francisco, centro simbólico de la ciudad.

- Parques de proximidad. De menor porte, aunque siempre mayores de $10.000 \mathrm{~m}^{2}$, cuentan habitualmente con una dotación en áreas verdes y mobiliario suficiente, pero sin tamaño ni instalaciones capaces de atraer usuarios más allá de su entorno.

- Espacios complementarios. Pequeños parques, plazas, calles peatonales, etc.

En todos los sentidos, los estándares de zonas verdes y espacios libres de Oviedo pueden considerarse muy aceptables; así, considerando sólo los grandes parques y los de proximidad, habría casi 13 metros cuadrados por vivienda y con adecuada distribución, pues el $98 \%$ de las viviendas estaría a menos de diez minutos. Si además se incluyen los espacios complementarios, casi el $99 \%$ de las viviendas estaría a menos de cinco minutos de una zona verde o espacio libre.

Otro indicador añadido son las zonas de juegos infantiles, donde prácticamente la totalidad de las viviendas están a menos de diez minutos. 
Ortega Montequín, M. (2019): "La accesibilidad peatonal a dotaciones de proximidad como pauta para la ordenación urbana. Oviedo como ejemplo metodológico”, GeoFocus (Artículos), $n^{\circ}$ 23, p. 3-18. ISSN: 1578-5157 http://dx.doi.org/10.21138/GF.629

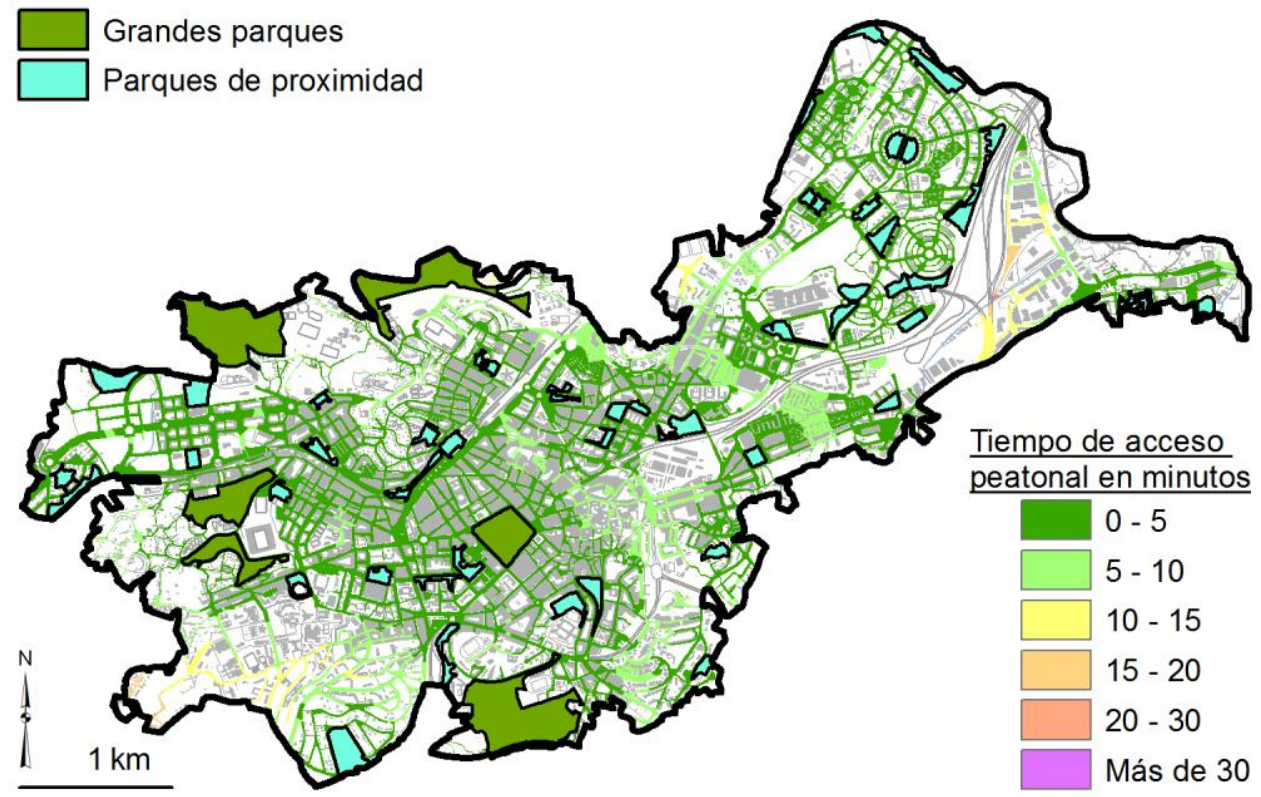

Figura 8. Accesibilidad a parques.

Fuente: Educastur. Base: MTN25 vectorial, IGN.

\subsection{Tablas resumen}

Tabla 1. Viviendas según tiempo de acceso peatonal a dotaciones de proximidad

\begin{tabular}{|c|c|c|c|c|c|c|}
\hline \multicolumn{7}{|c|}{ Por tiempo de acceso peatonal. Unidad: $\mathrm{n}^{\circ}$ de viviendas } \\
\hline Minutos: & $\begin{array}{c}\text { Menos } \\
\text { de } 5\end{array}$ & $\begin{array}{c}\text { De } 5 \text { a } \\
10\end{array}$ & $\begin{array}{c}\text { De } 10 \text { a } \\
15\end{array}$ & $\begin{array}{c}\text { De } 15 \text { a } \\
20\end{array}$ & $\begin{array}{c}\text { De 20 a } \\
30\end{array}$ & $\begin{array}{l}\text { Más de } \\
\text { 30 }\end{array}$ \\
\hline $\begin{array}{l}\text { Centros sanitarios de atención } \\
\text { primaria }\end{array}$ & 37.274 & 53.340 & 21.778 & 3.848 & 330 & 21 \\
\hline \multicolumn{7}{|l|}{ Centros escolares } \\
\hline Colegios públicos & 48.661 & 50.601 & 13.752 & 3.440 & 137 & 0 \\
\hline $\begin{array}{l}\text { Colegios públicos + Centros } \\
\text { concertados }\end{array}$ & 68.784 & 34.519 & 10.682 & 2.409 & 197 & 0 \\
\hline $\begin{array}{l}\text { Instituto de Educación } \\
\text { Secundaria público }\end{array}$ & 23.059 & 40.506 & 35.277 & 11.807 & 2.836 & 3.106 \\
\hline $\begin{array}{l}\text { Instituto de Educación } \\
\text { Secundaria público + Centro } \\
\text { concertado }\end{array}$ & 47.253 & 38.173 & 19.276 & 8.129 & 2.674 & 1.086 \\
\hline \multicolumn{7}{|l|}{ Zonas verdes y espacios libres } \\
\hline Grandes parques & 20.857 & 33.067 & 25.793 & 9.312 & 12.344 & 15.218 \\
\hline $\begin{array}{l}\text { Grandes parques + parques y } \\
\text { espacios de proximidad }\end{array}$ & 93.625 & 20.476 & 1.476 & 89 & 52 & 873 \\
\hline
\end{tabular}


Ortega Montequín, M. (2019): "La accesibilidad peatonal a dotaciones de proximidad como pauta para la ordenación urbana. Oviedo como ejemplo metodológico", GeoFocus (Artículos), $n^{\circ} \quad 23, \quad$ p. 3-18. ISSN: $1578-5157$ http://dx.doi.org/10.21138/GF.629

Por tiempo de acceso peatonal. Unidad: $\mathrm{n}^{\circ}$ de viviendas

\begin{tabular}{|l|c|r|r|r|r|r|}
\hline \multicolumn{1}{|c|}{ Minutos: } & $\begin{array}{c}\text { Menos } \\
\text { de 5 }\end{array}$ & $\begin{array}{c}\text { De 5 a } \\
\mathbf{1 0}\end{array}$ & $\begin{array}{c}\text { De 10 a } \\
\mathbf{1 5}\end{array}$ & $\begin{array}{c}\text { De 15 a } \\
\mathbf{2 0}\end{array}$ & $\begin{array}{c}\text { De 20 a } \\
\mathbf{3 0}\end{array}$ & $\begin{array}{c}\text { Más de } \\
\mathbf{3 0}\end{array}$ \\
\hline $\begin{array}{l}\text { Grandes parques + parques de } \\
\text { proximidad + espacios } \\
\text { complementarios }\end{array}$ & & & & & \\
\hline Áreas de juegos infantiles & 94.978 & 20.878 & 735 & 0 & 0 & 0 \\
\hline
\end{tabular}

Tabla 2. Porcentaje de viviendas según tiempo de acceso peatonal a dotaciones de proximidad. Valores acumulados.

\begin{tabular}{|c|c|c|c|c|c|}
\hline \multicolumn{6}{|c|}{ Por tiempo de acceso peatonal, en porcentaje de viviendas } \\
\hline Minutos: & \begin{tabular}{|c|} 
Menos de \\
5
\end{tabular} & $\begin{array}{c}\text { Menos de } \\
10\end{array}$ & $\begin{array}{l}\text { Menos de } \\
15\end{array}$ & $\begin{array}{c}\text { Menos de } \\
20\end{array}$ & $\begin{array}{c}\text { Menos de } \\
30\end{array}$ \\
\hline $\begin{array}{l}\text { Centros sanitarios de atención } \\
\text { primaria }\end{array}$ & 31,97 & 77,72 & 96,40 & 99,70 & 99,98 \\
\hline \multicolumn{6}{|l|}{ Centros escolares } \\
\hline Colegios públicos & 41,74 & 85,14 & 96,93 & 99,88 & 100,00 \\
\hline $\begin{array}{l}\text { Colegios públicos + Centros } \\
\text { concertados }\end{array}$ & 59,00 & 88,60 & 97,76 & 99,83 & 100,00 \\
\hline $\begin{array}{l}\text { Instituto de Educación } \\
\text { Secundaria público }\end{array}$ & 19,78 & 54,52 & 84,78 & 94,90 & 97,34 \\
\hline $\begin{array}{l}\text { Instituto de Educación } \\
\text { Secundaria público + Centro } \\
\text { concertado }\end{array}$ & 40,53 & 73,27 & 89,80 & 96,78 & 99,07 \\
\hline \multicolumn{6}{|l|}{ Zonas verdes y espacios libres } \\
\hline Grandes parques & 17,89 & 46,25 & 68,37 & 76,36 & 86,95 \\
\hline $\begin{array}{l}\text { Grandes parques }+ \text { parques de } \\
\text { proximidad }\end{array}$ & 80,30 & 97,86 & 99,13 & 99,21 & 99,25 \\
\hline $\begin{array}{l}\text { Grandes parques }+ \text { parques de } \\
\text { proximidad + espacios } \\
\text { complementarios }\end{array}$ & 98,66 & 99,66 & 100,00 & 100,00 & 100,00 \\
\hline Áreas de juegos infantiles & 81,46 & 99,37 & 100,00 & 100,00 & 100,00 \\
\hline
\end{tabular}

\section{Discusión y valoración de hallazgos}

Más que comparar los resultados con otras investigaciones, cabe contrastar los métodos que se utilizaron en otros estudios y su utilidad para el cometido de éste; así, se efectuaron una serie de pruebas para testar (control de resultados de los modelos frente a recorridos peatonales reales), contrastar y decidir cuál aplicar; a los comentados en el capítulo 2 se le añadió el servicio Openroute $^{5}$. Se realizaron a partir un único equipamiento, el centro de educación primaria y 
Ortega Montequín, M. (2019): "La accesibilidad peatonal a dotaciones de proximidad como pauta para la ordenación urbana. Oviedo como ejemplo metodológico", GeoFocus (Artículos), $n^{\circ} \quad 23, \quad$ p. 3-18. ISSN: $1578-5157$ http://dx.doi.org/10.21138/GF.629

secundaria concertado Masaveu, que cumple con algunos condicionantes claves en la temática tratada, tales como una barrera (una autovía, en este caso), manzanas grandes, viales privados y zonas verdes con un diseño más enfocado hacia el paseo que hacia la funcionalidad. El resultado se ha simplificado en la figura 9, donde se representa la distancia peatonal de diez minutos.

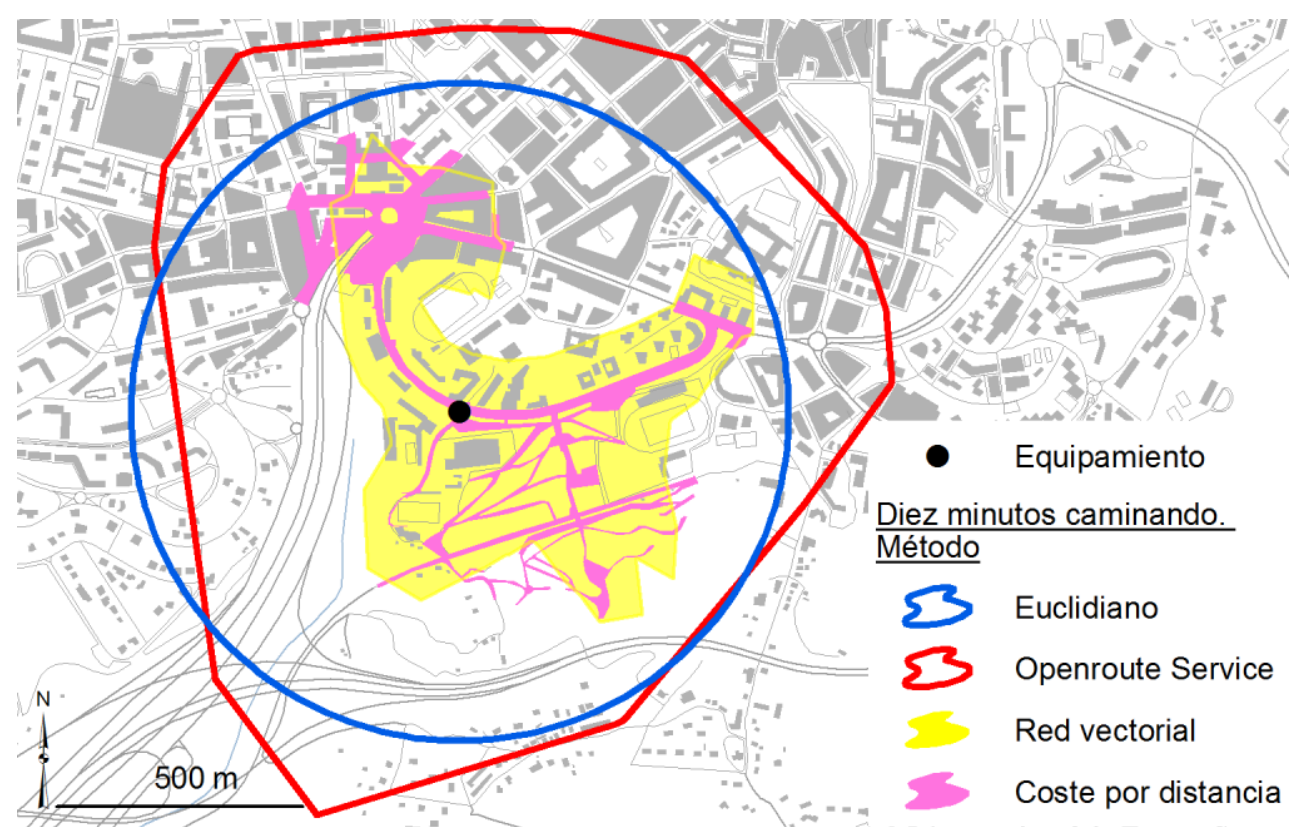

Figura 9. Comparación de métodos.

Base: MTN25 vectorial, IGN.

De los resultados obtenidos se puede señalar lo siguiente:

- El sistema euclidiano puede emplearse como referencia, pero no debe llegar a alcanzar la consideración de análisis de accesibilidad por cuanto obvia completamente todo tipo de barreras físicas.

- Openroute Service presenta importantes limitaciones, como no poder graduar la velocidad (sólo se puede aplicar la que viene por defecto, lo que supone también no poder utilizarlo para comparar diferentes grupos sociales, por ejemplo; por lo que se aprecia, su modelo usa una velocidad mayor de los $4 \mathrm{~km} / \mathrm{h}$ considerados en este estudio), y, a la vista del resultado, tampoco tiene en cuenta las barreras físicas.

- El empleo de redes vectoriales y el de coste por distancia (ráster), por la prueba realizada, arrojan resultados similares y más ajustados a la realidad que los métodos anteriores. En ambos casos, permite graduar los atributos (velocidad, fundamentalmente) y realizar simulaciones (por ejemplo, lo que supondría abrir un viario público peatonal hacia el norte desde el equipamiento señalado en la figura 8).

De lo señalado cabe concluir que los métodos de redes vectoriales y coste por distancia (ráster) son válidos, por lo que la elección entre ambos habrá de depender de la información base con que se cuente. Sobre esto se puede realizar el siguiente ensayo conclusivo: 
Ortega Montequín, M. (2019): "La accesibilidad peatonal a dotaciones de proximidad como pauta para la ordenación urbana. Oviedo como ejemplo metodológico", GeoFocus (Artículos), $n^{\circ} \quad 23, \quad$ p. 3-18. ISSN: $1578-5157$ http://dx.doi.org/10.21138/GF.629

- El análisis de redes vectoriales puede ser de rápido manejo si se cuenta con una red previa que presente una topología adecuada, puesto que su producción suele resultar lenta y costosa; productos como OpenStreetMap (versión descargable) o CartoCiudad y Redes de Transporte del Instituto Geográfico Nacional (para España) cuentan con buena calidad, aunque sea obligado revisarlas, ajustarlas y completarlas en lo que se refiere a espacios no aptos para el uso peatonal, espacios peatonales no contemplados, etc. Deben revisarse también los arcos (líneas) más largos, pues alteran los cálculos de isocronas.

- El coste por distancia, por su parte, facilita la obtención del espacio peatonal cuando no se cuenta con una red previa o cuando ésta requiera de un exceso de ajuste; con bases como los mapas topográficos o catastrales suelen conseguirse los espacios peatonales en un tiempo menor que estableciendo una red; y lo mismo ocurre en el caso de proyectos (como, por ejemplo, de Planes Parciales que desarrollen suelos urbanizables).

- En el caso de las redes, el cálculo se ciñe a la propia red modelada, con lo que las isocronas son extrapolaciones; por otra parte, el uso del coste por distancia emplea la totalidad del espacio.

La semiología, por su lado, está directamente relacionada con la escala de representación de los resultados; así, en escalas pequeñas las isocronas resultantes de las herramientas de análisis de redes vectoriales son más representativas, mientras que en mapas de mayor detalle el efecto "venoso" del coste por distancia resulta más descriptivo; aun así, hay casos como el de Prat et al (2009) que aplican esta representación para toda Cataluña con buen resultado.

\section{Conclusiones}

Los equipamientos de proximidad y los espacios verdes son dotaciones que contribuyen de un modo directo a la mejora de la calidad de vida urbana. Por ello, aquellos equipamientos que cumplan su función como equipamientos de proximidad, así como las zonas verdes, deberían contar con una evaluación previa respecto de su accesibilidad peatonal; para ello, métodos de análisis vectoriales de red y de coste por distancia (ráster) dan muy buenos resultados y facilitan de un modo sustancial la toma de decisiones.

En definitiva, se puede conseguir mejorar de un modo relevante la planificación de espacios urbanos, si bien cabe señalar que en ciudades como Oviedo, donde se ha aplicado el método descrito en este artículo, así como en buena parte de las ciudades de Europa occidental, suelen contar con abundantes dotaciones (y no sólo de proximidad), lo que conlleva que las acciones del planeamiento se limiten a mejoras, mientras que en gran parte del mundo, con un déficit dotacional mayor y menor disponibilidad de fuentes, el método descrito debería ser parte capital de la planificación urbana.

Los resultados del método ensayado son lo suficientemente satisfactorios como para darlo a conocer de manera que sirva de referencia para una más adecuada planificación urbana.

\section{Referencias bibliográficas}

Arranz López, A.; Zúñiga Antón, M.; Solanas Jiménez, J.; López Escolano, C.; Postigo Vidal, R.; Salinas Solé, C. y Pueyo Campos, A. (2012): "Representación y análisis de los indicadores de 
Ortega Montequín, M. (2019): "La accesibilidad peatonal a dotaciones de proximidad como pauta para la ordenación urbana. Oviedo como ejemplo metodológico", GeoFocus (Artículos), $n^{\circ} \quad 23, \quad$ p. 3-18. ISSN: $1578-5157$ http://dx.doi.org/10.21138/GF.629

sostenibilidad urbana de la agenda XXI para la planificación de los equipamientos y servicios urbanos en Zaragoza", La población en clave territorial. Procesos, estructuras y perspectivas de análisis. Actas del XIII Congreso de la Población Española. Santander, Ministerio de Economía y Competitividad, Gobierno de Cantabria, Asociación de Geógrafos Españoles y Universidad de Cantabria. Págs. 28 -37.

Astursalud (portal web de la Consejería de Sanidad del Principado de Asturias): https://www.astursalud.es/categorias/-/categorias/ciudadania/04000mapa-sanitario

Ayto. Bilbao (2016): Avance del Plan General de Ordenación Urbana de Bilbao.

Ayto. Oviedo (2006): Plan General de Ordenación Urbana.

Ayto. Vigo (2016): Borrador de Plan Xeral de Ordenación Municipal do Concello do Vigo.

Basoa Rivas, G.; Otero Puime, A. (1994): “Accesibilidad geográfica a los centros de salud y planeamiento urbanístico en Fuenlabrada (Madrid)", Rev San Hig Pub, $n^{o}$ 68, pp. 503-511.

CNIG (2012): CartoCiudad, Centro Nacional de Información Geográfica.

De La Fuente, H.E., Rojas, C. y Salado, M.J. (2013): "Distribución de los equipamientos educativos. Evidencias de inequidad espacial en la educación del área metropolitana de Concepción", GeoFocus, $n^{o}$ 13-2, p. 231-257.

Decreto 278/2007, de 4 de diciembre, por el que se aprueba el Reglamento de Ordenación del Territorio y Urbanismo del Principado de Asturias (ROTU).

Dirección General del Catastro: Cartografía en formato vectorial (shp) e información alfanumérica (cat), http://www.catastro.minhap.gob.es/esp/productos.asp.

Educastur (portal web de la Consejería de Educación del Principado de Asturias): https://servicios.educastur.es/Educastur/centros/mapa/OviedoEducacion/ovi.html

Escalona Orcao, A.I., Díez Cornago, C. (2003): “Accesibilidad geográfica de la población rural a los servicios básicos de salud: estudio en la provincia de Teruel”, Revista de Estudios sobre Despoblación y Desarrollo Rural, $n^{\circ} 3$, p. 111-149.

Escalona Orcao, A.I., Díez Cornago, C. (2005): "Retos y problemas de la accesibilidad a servicios en zonas despobladas: un caso en la provincia de Teruel (España)", Scripta Nova, Revista electrónica de Geografía y Ciencias Sociales, Vol. IX núm. 188.

Esquivel-Cuevas, M.; Hernández-Mercado, O.; Garnica-Monroy, R. (2013): "Modelo de accesibilidad peatonal (MAP). Índice de accesibilidad peatonal a escala barrial", Revista Bitácora Urbano Territorial, vol 23, pp. 21-30.

García-Palomares, J. C., Sousa Ribeiro, J., Gutiérrez, J., \& Sá Marques, T. (2018). “Analysing proximity to public transport: the role of Street network design", Boletín de la Asociación de Geógrafos Españoles, 76, pp.102-130.

Garnica Berrocal, R (2012): “Análisis espacial de los equipamientos educativos (oficiales) en la ciudad de Montería, Colombia”, Estudios socioterritoriales, vol. 12.

Instituto Geográfico Nacional: CartoCiudad, Centro Nacional de Información Geográfica (Centro de Descargas, http://centrodedescargas.cnig.es/CentroDescargas/). 
Ortega Montequín, M. (2019): "La accesibilidad peatonal a dotaciones de proximidad como pauta para la ordenación urbana. Oviedo como ejemplo metodológico", GeoFocus (Artículos), $n^{\circ} \quad 23, \quad$ p. 3-18. ISSN: $1578-5157$ http://dx.doi.org/10.21138/GF.629

Instituto Geográfico Nacional: Mapa Topográfico Nacional a escala 1:25.000 vectorial (MTN25 vectorial), Centro Nacional de Información Geográfica (Centro de Descargas, http://centrodedescargas.cnig.es/CentroDescargas/).

Instituto Geográfico Nacional: Redes de transporte, Centro Nacional de Información Geográfica (Centro de Descargas, http://centrodedescargas.cnig.es/CentroDescargas/).

Instituto Nacional de Estadística: Estadísticas diversas, http://www.ine.es/

Hernández Aja, A. (2000): "Barrios y equipamientos públicos, esencia del proyectos democrático de la ciudad", Documentación Social, $n^{o} 119$, pp. 79-93.

Moro Deordal, I.; Villaescusa Ealo, J. (2000): "Estudio de la Accesibilidad Espacial de los Centros de Enseñanza Primaria en Bilbao", Tecnologías Geográficas para el Desarrollo Sostenible, 2000, pp. 718-734.

Olivera, A. (1993): Geografía de la salud. Madrid, Editorial Sintesis.

Ortega Montequín, M; Méndez García, B. (2012): “The Location of Subregional Facilities in Territories with Scattered Population. A Methodological Proposal Based on the Case of Asturias (Spain)", Journal of Settlements and Spatial Planning, vol3. $n^{o} 2$, pp. 103-110.

OSM: OpenStreetMap \& Contributions (https://www.openstreetmap.org/)

París Roche, A. (2003): MIDE. Método para la Información de Excursiones, Federación Aragonesa de Montañismo.

PNOA (2017): Ortofoto de 2017 del Plan Nacional de Ortofotografía Aérea, Centro Nacional de Información Geográfica.

Prat, E.; Sánchez, J.; Pesquer, L1.; Olivet, M.; Aloy, J.; Fusté, J. y Pons, X. (2008): “Estudio sobre la accesibilidad de los centros sanitarios públicos de Cataluña", XIII Congreso Nacional de Tecnologías De La Información Geográfica.

Prat, E., Pesquer, L1., Olivet, M., Aloy, J., Fuste, J. y Pons, X. (2009): “Metodología para el análisis de accesibilidad a los recursos sanitarios: el caso de Cataluña", GeoFocus, no 9, p. 250-269.

Ramírez, L. (2003): “Cálculo de medidas de accesibilidad geográfica, temporal y económica generadas mediante Sistemas de Información Geográfica", Primer Congreso de la Ciencia Cartográfica y VIII Semana Nacional de Cartografía, Buenos Aires, junio de 2003.

Ramírez, L. (2006): "La accesibilidad y la movilidad espacial. Posible tratamiento mediante Sistemas de Información Geográfica", Cuadernos de Ideas $N^{2} 2$.

Ramírez, L. (2009): Planificación territorial sanitaria y Sistemas de Información Geográfica. Una aproximación al conocimiento de la accesibilidad de la población a los equipamientos hospitalarios y de la localización óptima de hospitales públicos en la Provincia del Chaco, Repositorio Institucional de la Universidad Nacional del Nordeste.

Real Academia Española (2017): Diccionario de la lengua española (DRAE), versión on line (http://dle.rae.es).

Salinas, C.; Arranz, A.; López, C.; Pueyo, A.; Solanas, J.; Zúñiga, M. (2012): "Valoración cartográfica de la proximidad a los equipamientos y servicios en escenarios de crisis: el caso de la 
Ortega Montequín, M. (2019): "La accesibilidad peatonal a dotaciones de proximidad como pauta para la ordenación urbana. Oviedo como ejemplo metodológico", GeoFocus (Artículos), $n^{\circ} \quad 23, \quad$ p. 3-18. ISSN: $1578-5157$ http://dx.doi.org/10.21138/GF.629

ciudad Zaragoza", XV Congreso Nacional de Tecnologías de la Información Geográfica, Madrid, AGE-CSIC, 19-21 de Septiembre de 2012.

${ }^{1}$ Artículo 10 del Reglamento de Ordenación del Territorio y Urbanismo del Principado de Asturias.

${ }^{2}$ ROTU, artículo 10:

«construcciones, instalaciones y espacios asociados que se destinen a la prestación de servicios básicos a la comunidad, de carácter educativo, cultural, sanitario, asistencial, religioso, comercial, deportivo, administrativo, de ocio, de transporte, de seguridad y otros análogos, incluidas las plazas de aparcamiento anejas y las superficies cubiertas con vegetación complementarias de los equipamientos. Pueden ser de titularidad pública o privada»

${ }^{3}$ Equipamientos y actividades comerciales; no se debe confundir con los "servicios urbanos" que define el citado Reglamento, fundamentalmente infraestructuras

${ }^{4}$ ROTU, artículo 10:

«d) Zonas verdes, destinadas a parques y jardines para el ocio y esparcimiento de la población.

e) Espacios libres: conjunto de espacios e instalaciones asociadas, destinados al ocio cultural o recreativo de la población.»

5 Openroute Service es una herramienta de la que no consta su empleo ni en planeamientos ni en publicaciones científicas, cuyo uso está siendo creciente en diferentes ámbitos (algunos planes de movilidad sostenible en proceso de redacción la están empleando como apoyo) por lo sencillo que resulta su manejo: funciona a través de un complemento de QGis (OSM Tools) y directamente sobre el servicio de cartografía de OpenStreetMap. 